\title{
Knee Osteoarthritis: A Primer
}

\author{
Michelle J Lespasio, DNP, JD, ANP; Nicolas S Piuzzi, MD; M Elaine Husni, MD, MPH; \\ George F Muschler, MD; AJ Guarino, PhD; Michael A Mont, MD \\ Perm J 2017;21:16-183
}

E-pub: 09/13/2017

https://doi.org/10.7812/TPP/16-183

\begin{abstract}
The purpose of this article is to provide a synopsis of the current medical understanding of knee osteoarthritis. We describe the prevalence, causes and associated risk factors, symptoms, diagnosis and classification, and treatment options. A quiz serves to assist readers in their understanding of the presented material.
\end{abstract}

\section{INTRODUCTION}

Please see the Sidebar: Quiz to Assess Knowledge of Knee Osteoarthritis (True/ False/Depends) with Answers.

Osteoarthritis (OA), also known as degenerative joint disease, primary $\mathrm{OA}$, wearand-tear arthritis, or age-related arthritis, is a leading cause of disability in the US and worldwide. ${ }^{1}$ Clinicians use the word arthritis to mean inflammation of the joints. In public health sectors, arthritis is a blanket term used to refer to more than 100 rheumatic diseases and conditions that affect the joints, the tissues surrounding the joints, and other connective tissue. Discussion of all these conditions is beyond the scope of this primer, and we will focus on primary OA of the knee.

$\mathrm{OA}$ is the most common joint disorder in the US. ${ }^{2}$ The number of people affected with symptomatic knee OA is likely to increase because of the aging of the population and the obesity epidemic. ${ }^{3}$

Knee OA affects the 3 compartments of the knee joint (medial, lateral, and patellofemoral joint) and usually develops slowly over 10 to 15 years, interfering with daily life activities. ${ }^{4}$ Traditionally, it was interpreted as a "wear-and-tear" of the articular cartilage disease only because of aging and not related to inflammation. Although the disease pathophysiology is still poorly understood and is under investigation, it is accepted that knee OA is multifactorial in origin. Whereas both inflammatory and biomechanical whole-organ disease processes play an important role, knee OA is also influenced by a combination of factors, including family history, age, obesity, diabetes, synovitis, systemic inflammatory mediators, innate immunity, lower limb alignment (genu valgum and genu varum), joint shape and dysplasia, trauma, and inflammation by metabolic syndromes. ${ }^{5-12}$ Regardless of the underlying mechanism, OA implies articular cartilage damage, bony osteophyte formation, and sclerosis of the subchondral bone, and in advanced cases, subchondral cyst formation can be seen pathologically.

Risk factors related to the development of knee OA may be divided into nonmodifiable and modifiable. Nonmodifiable risk factors include hereditary (genetic mutations that may predispose an individual to the development of OA of the knee) and congenital (inherited abnormalities in the shape of the bone that surround the knee joint) factors. Modifiable risk factors can be targeted for treatment. The most common modifiable risk factor in the US is overweight; every pound $(0.45 \mathrm{~kg})$ of weight gained adds $2 \mathrm{lbs}$ to $4 \mathrm{lbs}(0.9-1.8 \mathrm{~kg})$ of extra pressure on one's

\section{Quiz to Assess Knowledge of Knee Osteoarthritis (True/False/Depends) with Answers:}

1. Surgery is required to treat knee osteoarthritis (OA).

Answer: Depends. Although surgery is not performed for most patients, surgery is necessary for those with severe pain or joint damage.

2. Knee OA may occur by wearing high heels.

Answer: Depends. Long exposure to wearing high heels does, in fact, generate altered forces at the knee when walking, which may predispose to degenerative changes in the joint and increase the risk of $\mathrm{OA}$.

3. There is an association between weather and knee $O A$.

Answer: Depends. Rainy climates do not cause OA, but those with $O A$ may have increased pain during rainy weather.

4. Knee OA will limit one's ability to exercise.

Answer: Depends. One will need to avoid high-impact exercise but should maintain a low-impact exercise routine.

5. One is more likely to develop knee OA if a parent had knee OA. Answer: Depends. One is at a higher risk of OA with a family history, but development is avoidable through a healthy lifestyle.

6. For every pound of weight gained, there is an equal amount of pound pressure on the knees. Answer: False. A 1-lb $(0.45 \mathrm{~kg})$ increase in weight equals approximately $2 \mathrm{lbs}$ to $4 \mathrm{lbs}(0.9$ to $1.8 \mathrm{~kg})$ of pressure on the knees.

7. Knee OA is a serious health problem.

Answer: True. Arthritis is the most common cause of disability in the US, affecting about 1 in every 5 US adults and their families. The economic burden is also large, with estimated costs of more than $\$ 188$ billion a year: $\$ 108$ billion in lost wages and $\$ 80$ billion in medical care.

8. Knee $O A$ is a normal consequence of aging. Answer: False. Even though knee OA is associated with aging, it is not a normal consequence of it.

Michelle J Lespasio, DNP, JD, ANP, is an Assistant Professor and Adult Nurse Practitioner in Orthopedic Surgery at the Boston Medical Center in MA. E-mail: michelle.lespasio@bmc.org. Nicolas S Piuzzi, MD, is an Orthopedic Regenerative Medicine and Cellular Therapy Fellow at the Cleveland Clinic in OH. E-mail: piuzzin@ccf.org. M Elaine Husni, MD, MPH, is a Rheumatologist and Immunologist and Director of the Arthritis \& Musculoskeletal Treatment Center in the Department of Rheumatologic and Immunologic Disease at the Cleveland Clinic in OH. E-mail: husnie@ccf.org. George F Muschler, MD, is a Professor of Orthopedic Surgery, Director of the Regenerative Medicine Laboratory, and Attending Physician at the Cleveland Clinic in OH. E-mail: muschlg@ccf.org. AJ Guarino, PhD, is a Professor of Biostatistics formerly at Massachusetts General Hospital Institute of Health Professions in Boston and currently at New England College of Optometry in Boston. E-mail: ajguarino@gmail.com. Michael A Mont, MD, is the Chairman of Orthopedic Surgery at the Cleveland Clinic in OH. E-mail: montm@ccf.org. 
knees. Excess weight increases joint loading, resulting in deleterious effects on weightbearing joints, and contributes with negative effects related to inflammation.

The diagnosis relies on the history and physical examination findings and is often confirmed with $x$-rays. Laboratory tests are usually reserved to rule out other diagnoses. Modern treatments focus on improving function and quality of life. They now range beyond nonsteroidal anti-inflammatory drugs (NSAIDs) and acetaminophen for mild arthritis to braces, physical therapy, weight loss, transcutaneous electrical nerve stimulation (TENS) units, and intraarticular cellular injections. The definitive treatment of severe arthritis remains one of the many types of surgeries.

\section{PREVALENCE}

Knee OA affects most adults aged 65 or older, with a prevalence in the US of $33.6 \%$ (12.4 million). ${ }^{2}$ Women have a greater prevalence $(42.1 \%)$ than do men $(31.2 \%){ }^{4}$ Women with radiographic knee OA are more likely to have symptoms than men, and African Americans generally report more knee and hip symptoms than do whites. ${ }^{13}$ Strenuous physical activity, especially activities requiring kneeling, knee-bending, squatting, and prolonged standing, as well as knee trauma and injury have also been linked to a high prevalence of symptomatic knee OA. ${ }^{3}$

Knee OA has a higher prevalence rate compared with other types of OA. ${ }^{14}$ The incidence of knee OA increases both with age and with longer lifetime and higher average weight of the population, particularly in obese women. ${ }^{15}$

\section{CAUSES AND RISK FACTORS}

Previously OA was thought to be a normal consequence of aging and the mechanical consequence of "wear and tear," thereby leading to the term degenerative joint disease. However, it is now realized that OA results from a multifactorial, complex interplay of constitutional and mechanical factors, including joint integrity, genetic predisposition, local inflammation, mechanical forces, and cellular and biochemical processes. ${ }^{5-12}$ Knee OA is closely associated with age, as radiographic evidence of OA occurs in most people by age 65 years and in more than $75 \%$ of people older than age 75 years. ${ }^{16}$ Although there are many associations and mechanisms that are not well understood, it has been reported that there is a higher prevalence of OA among elderly women. ${ }^{16}$

There are three compartments in the knee: 1) the medial tibiofemoral compartment, which joins the medial tibial plateau to the medial femoral condyle; 2) the lateral tibiofemoral compartment, which joins the lateral tibial plateau to the lateral femoral condyle; and 3) the patellofemoral joint, which joins the kneecap to the femur. These three compartments work together to form a modified hinge joint that allows the knee to bend and straighten, and to rotate slightly from side to side. Excess weight on the knee can adversely affect the functional capacity of the knee joint.

An association between obesity (body mass index) and the prevalence and incidence of knee OA has been consistently demonstrated in several cross-sectional and longitudinal studies. ${ }^{17}$ Although excess weight increases joint loading, resulting in deleterious effects on weight-bearing joints, this is not the only factor involved in the relationship between OA and obesity. Obesity increases the risk of knee OA by multiple mechanisms: Increased joint loading; changes in body composition, with negative effects related to inflammation; and behavioral factors, such as diminished physical activity and subsequent loss of protective muscle strength. ${ }^{18}$ Furthermore, it is expected that the prevalence of obesity is unlikely to decline and will probably increase the incidence of knee OA and the demand for knee arthroplasty. ${ }^{19}$

\section{SYMPTOMS OF KNEE OSTEOARTHRITIS}

Knee symptoms can vary depending on the cause of the problem. The most common symptom of knee OA is pain around the knee joint. Pain can be dull, sharp, constant, or intermittent (off and on). Pain can vary from mild to agonizing. Range of motion can be decreased. The practitioner may hear grinding or popping sounds and may report muscle weakness. Swelling, locking, and giving way of the knee are common problematic symptoms. These disabilities, mainly related to pain, are usually manifested by difficulty in walking, climbing stairs, performing household chores, and sitting upright and have a negative psychological impact, all of which can lead to a decreased quality of life. ${ }^{20}$
Knee pain can develop slowly and worsen over time (most common), or pain can have a sudden onset. Pain and stiffness in the morning, after sitting, or after prolonged rest are most common. Over time, painful symptoms may occur more frequently, including during rest or at night. Typically, pain flares up with vigorous activity. Joint pain and stiffness after sitting or prolonged rest typically loosen up in less than 30 minutes, known as gelling.

\section{DIAGNOSIS AND CLASSIFICATION}

The classification and diagnosis of knee OA should begin with a review of the different types of knee OA. OA of the knee has traditionally been classified by etiology into either idiopathic (ie, primary) or secondary forms. Idiopathic OA of the knee is usually localized but can be generalized if knee OA involves three or more joint sites. Knee OA can also be classified by anatomic involvement by the chief joint involved.

Before the practitioner makes a clinical diagnosis of idiopathic knee OA, secondary underlying disorders should be considered and excluded. Secondary conditions of the knee that may enhance the risk of knee OA should be examined carefully. These conditions include trauma, congenital or developmental disorders, calcium pyrophosphate dihydrate deposition disease, and other bone and joint disorders such as osteonecrosis, rheumatoid arthritis, gouty arthritis, septic arthritis, and Paget disease of the bone. ${ }^{21}$ Of all secondary $\mathrm{OA}$, posttraumatic $\mathrm{OA}$, caused by previous fractures of the distal femur and proximal tibia, constitutes the plurality of causes but accounts for only $12 \%$ of symptomatic OA. ${ }^{22}$ A clinical diagnosis of knee OA is supported by the presence of typical symptoms, physical examination findings, laboratory results, and imaging features. No single clinical feature is absolutely sensitive or specific. Generally, the more features that are present, the more likely the diagnosis.

When diagnosing knee OA, the health care practitioner should initially ask questions directed to chronic health conditions, history of known injury or trauma, previous surgery, medications, occupation, and symptoms (eg, pain level and location, morning stiffness). After the history evaluation, a focused physical examination should be conducted. Each patient should be examined for the presence of an effusion, loss of range 
of motion, and loss of smooth mechanical movement. The examination should assess for tenderness to palpation of the joint, crepitus (a grating sensation inside the joint) with movement, pain when pressure is placed on the joint, ability to ambulate (with description of any problems with ambulation), as well as signs of injury to muscles, tendons, and ligaments surrounding the joint. In addition, the examination should describe passive range of motion (assisted) and active (selfdirected) range of motion of the affected joint.

Goldberg $^{23}$ recommends the following as a common approach to the examination of all joints:

- Make sure the area is well exposed-no clothing covering either side. Patient gowns come in handy

- Carefully inspect the joint or joints in question. Are there signs of inflammation or injury (swelling, redness, warmth)? Deformity? Because many joints are symmetrical, compare it with the opposite side

- Understand normal functional anatomy. What does this joint normally do?

- Observe the joint while the patient attempts to perform normal activity. What can't the patient do? What specifically limits him/her? Was there a discrete event (eg, trauma) that caused this? If so, what was the mechanism of injury?

- Palpate the joint in question. Is there warmth? Point tenderness? If so, over what anatomic structures?

- Assess the range of motion, both active (patient moves it) and passive (you move it). If active range of motion is limited, determine causes of pain

- Perform strength and neurovascular assessments

- Perform specific provocative maneuvers related to pathology occurring in that joint (Goldberg ${ }^{23}$ presents some for each joint)

- In the setting of acute injury and pain, it is often very difficult to assess a joint because the patient "protects" the affected area, limiting movement and thus your examination. It helps to examine the unaffected side first. This will help to set the patient at ease and will help the physician to gain a sense of the patient's normal range of motion.

Radiologic evaluation may be used to make a diagnosis of knee OA. The American College of Rheumatology, however, suggests that a clinician can make a secure

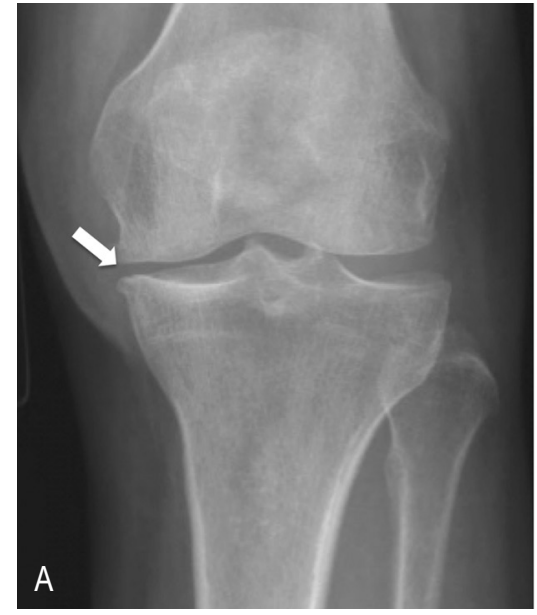

Figure 1A. Anterior-posterior (AP) radiograph of a left knee with mild osteoarthritis (OA; Kellgren and Lawrence Grade 1). The arrow indicates doubtful joint space narrowing and possible osteophytic lipping.

diagnosis of knee OA without radiologic evidence. X-rays may be used to assess the condition of the joint, to reveal the presence, or lack thereof, of fractures, dislocations, and joint space narrowing (JSN). JSN occurs as cartilage is lost, and the joint space between the bone narrows. X-rays of an arthritic knee or hip may show a narrowing of the joint space because of cartilage loss, changes in the bone, and formation of bone spurs (osteophytes) caused by bone remodeling.

The most frequent radiographic grading system is described by Kellgren and Lawrence. ${ }^{24}$ In this system, Grade 1 is characterized by doubtful JSN and possible osteophytic lipping (Figure 1A); Grade 2, by definite osteophytes and possible JSN on anteroposterior weight-bearing radiograph (Figure 1B); Grade 3, by multiple osteophytes, definite JSN, sclerosis, and possible bony deformity (Figure 2A); and Grade 4, by large osteophytes, marked JSN, severe sclerosis, and definite bony deformity (Figure 2B).

Other imaging studies, such as magnetic resonance imaging, computed tomography, or a bone scan, although usually not required, may be needed to rule out other conditions of the bone and soft tissues of the joint.

Blood tests may be ordered to help determine what kind of arthritis a patient has and especially to rule out secondary causes. Among others, these are some of the common initial studies ordered: complete blood cell count with differential, erythrocyte

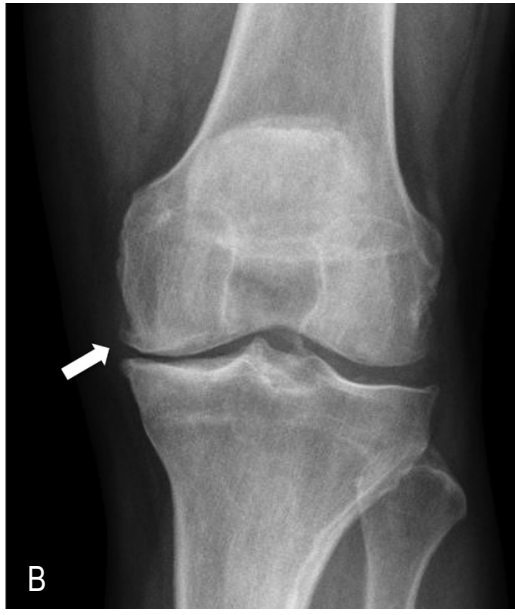

Figure 1B. AP radiograph of a left knee with moderate OA (Kellgren and Lawrence Grade 2). The arrow indicates definite osteophytes and possible joint space narrowing.

sedimentation rate, C-reactive protein, rheumatoid factor titers, and evaluation of synovial fluid. When the diagnosis of primary $\mathrm{OA}$ is made, these tests would be expected to be within normal limits, whereas patients with other types of rheumatologic conditions would have abnormal results of laboratory tests (eg, elevated erythrocyte sedimentation rate, elevated C-reactive protein concentration).

A diagnosis of knee OA can be reached only with clinical findings or with a combination of clinical and radiographic findings. There are multiple classification systems for OA. The European League Against Rheumatism recommended the use of 3 symptoms (persistent pain, limited morning stiffness, and reduced function) and 3 signs (crepitus, restricted range of motion, and bony enlargement) for making the diagnosis of knee OA. As more factors are present, the likelihood of having a diagnosis of OA increases. When all 6 signs and symptoms are present, the probability of seeing OA on radiographs is $99 \%{ }^{25}$

One of the clinical classification criteria most frequently used is the one developed by the American College of Rheumatology. ${ }^{26,27}$ These criteria start with the presence of knee pain plus specific characteristics. The number of characteristics associated with knee pain varies depending on whether a diagnosis is being made using clinical criteria only, using clinical and radiographic criteria, or using clinical and laboratory criteria, as follows: 
- Clinical: Knee pain for most days of the prior month, in addition to at least 3 of the following:

1. crepitus on active joint motion

2. morning stiffness less than 30 minutes' duration

3. age older than 50 years

4. bony enlargement of the knee on examination

5. bony tenderness of the knee on examination

6. no palpable warmth.

- Clinical plus radiographic: Knee pain for most days of the prior month, plus radiographic evidence of osteophytes on joint margins in addition to 1 of the following:

1. crepitus on active motion

2. morning stiffness less than $30 \mathrm{~min}$ utes' duration

3. age older than 50 years.

- Clinical plus laboratory: Knee pain for most days of the prior month, in addition to at least 5 of the following:

1. crepitus on active joint motion

2. morning stiffness less than 30 minutes' duration

3. age older than 50 years

4. bony tenderness to palpation

5. bony enlargement

6. no palpable warmth

7. erythrocyte sedimentation rate below $40 \mathrm{~mm} / \mathrm{h}$

8. rheumatoid factor less than 1:40

9. synovial fluid consistent with $\mathrm{OA}$ (white blood cell count $<2000 / \mu \mathrm{L}$ ).

\section{TREATMENT OPTIONS}

Treatment designed for knee OA should aim to relieve pain, improve function, and limit disabilities. Knee OA treatment is usually driven by the patient's symptoms and the potential to improve quality of life. Nonoperative treatments of knee OA are often useful for patients with Kellgren and Lawrence Grades 1 to 3 (Figures 1 and 2A), which are "early" stages of OA. However, surgical treatments are generally needed to cure or ameliorate advanced stages of knee OA (Grade 4; Figure 2B). ${ }^{28,29}$

\section{Nonsurgical Options}

Nonoperative treatments constitute the initial approach for patients who consult for the first time with knee pain and signs of knee OA. There are multiple therapeutic

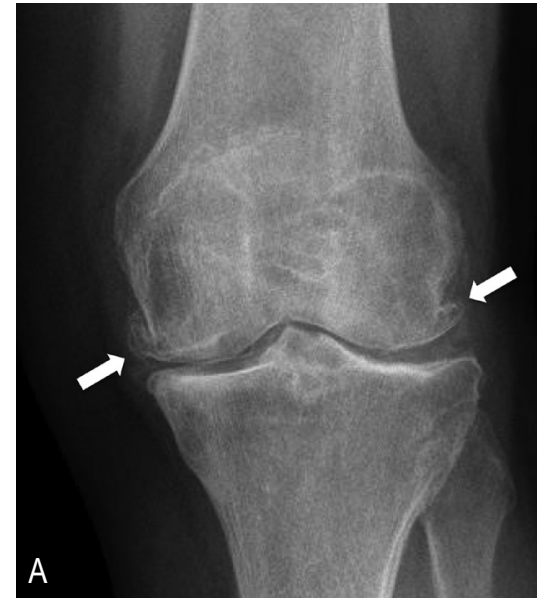

Figure 2A. Anterior-posterior (AP) radiograph of a left knee with moderate to severe osteoarthritis (OA; Kellgren and Lawrence Grade 3). The arrows indicate multiple osteophytes, definite joint space narrowing, sclerosis, and possible bony deformity.

options, and many times a patient needs to try multiple approaches until finding the most suitable therapy. Heat and cold treatments are effective pain relief methods. Heat treatments enhance circulation and soothe stiff joints and tired muscles, whereas cold treatments slow circulation, which reduces swelling, thus alleviating acute pain. The patient may need to experiment with heat and cold therapies to determine which is more effective to treat his/her specific symptoms. ${ }^{30}$

Treatment may include but is not limited to one or more of a large list of options: modifying the intensity of the activities performed, weight loss, muscle strengthening exercises, orthotics, osteopathic treatment, application of ice or heat, pharmaceutical treatment including NSAIDs, and viscosupplementation with hyaluronic acid injections, corticosteroid injections, glucosamine, and platelet-rich plasma (PRP). $\mathrm{PRP}$ is derived from a sample of the patient's own blood and then injected directly into the affected knee joint to reduce pain, improve joint function, and possibly repair the cartilage..$^{29,31}$ Quite often, an initial and more "simple" approach is to recognize triggers that aggravate symptoms and minimize those activities causing symptoms (eg, climbing stairs). Avoiding high-impact activities (eg, jogging) and switching to lower-impact activities (eg, swimming or cycling) may diminish stress on the knee

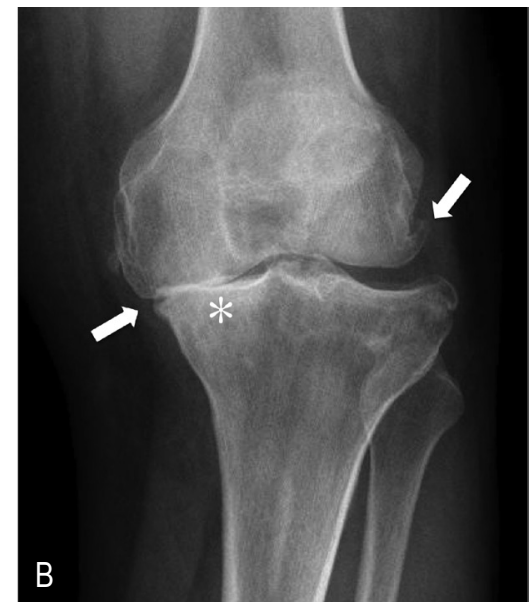

Figure 2B. AP radiograph of a left knee with severe $\mathrm{OA}$ (Kellgren and Lawrence Grade 4), showing large osteophytes (downward arrow at right), marked joint space narrowing (upward arrow at left), severe bone sclerosis (asterisk), and definite bony deformity in medial tibial plateau.

and improve the symptoms. Exercise and/ or other physical activity is recommended for improving pain and functional status in people with knee OA. ${ }^{32}$ Specific exercises can increase range of motion and flexibility and strengthen muscles in the knee. Many times, an individualized exercise program combined with effective behavioral strategies aimed at weight loss may be most beneficial for reducing pain in overweight patients. Both can be difficult, especially in patients who find it difficult to exercise because of their painful joints.

\section{Weight Loss}

Addressing one specific modifiable risk factor for knee OA is fundamental to successful management. Weight loss not only reduces the risk of incident knee OA but, in established disease, also reduces symptoms, improves function, and may reduce disease progression. ${ }^{18}$ Although weight loss approaches in knee OA are beyond the scope of this article, we cannot emphasize enough that weight loss must be encouraged at all available opportunities for appropriate patient care. There is some evidence suggesting that nonpharmacologic management strategies are underused by physicians in both primary and secondary care. ${ }^{33,34}$ Close collaboration among physicians and other health care professionals from various clinical and research spectrums within the health care system may provide the most effective solutions to these issues. 
Electrical Stimulation and Assistive Devices

Four nonoperative, noninvasive treatment modalities were identified in a recent systematic review of the literature to have a significant effect on the reduction of pain in knee OA. Those modalities identified included TENS, neuromuscular electrical stimulation, insoles, and bracing. Of note, most of the studies reviewed had less than a 6-month follow-up. ${ }^{35}$ An easily affordable electrical stimulator (costs vary and can range from $\$ 20$ on up) may be useful for treating knee $\mathrm{OA},{ }^{35}$ particularly in patients who are unable to perform an exercise program. TENS uses low-voltage electrical current to produce pain relief. This therapy uses a small, battery-powered machine that is connected to electrodes (wires that conduct electrical current) from the machine to the skin. The electrodes are often placed on the area of pain (eg, around the knee), creating a circuit of electrical impulses that travels along nerve fibers. The electrical current generates a sensation that is thought to block the pain signal from the nerve to where it is perceived in the brain as pain.

Neuromuscular electrical stimulation also involves the use of a device that transmits an electrical impulse to the skin over selected muscle groups. Neuromuscular electrical stimulation is intended to strengthen or maintain muscle mass of the treated muscles. Electrical stimulation placed on the quadriceps muscle may ease pain and strengthen the quadriceps muscles supporting the knee. It also may delay the need for total knee replacement.

Using assistive devices such as a cane, wearing shock-absorbing shoes or inserts, or wearing a knee brace or sleeve can help relieve symptoms. Assistive devices or walking aids, such as a cane or crutch, can reduce pain in patients with knee OA. ${ }^{36}$ Patients should be given instructions in the optimal use of an assistive device in the contralateral hand. ${ }^{36}$ Although evidence is fairly inconclusive, ${ }^{37}$ braces placed over the knee often assist with mobility and function; patients may find them especially helpful in arthritis located on either part of the knee. The rationale of an "unloader" brace is to shift weight away from the affected portion of the knee, whereas a "support" brace helps support the entire knee load. ${ }^{38}$ The aim with the use of a brace is to reduce symptoms, improve gait mechanics, and correct knee malalignment. ${ }^{39}$ Pneumatic unloader bracing with extension assists have been shown to strengthen the muscles around the knee. ${ }^{40}$ Additional research is required because the optimal choice for an orthosis remains unclear, and long-term implications for their effectiveness remain undefined. ${ }^{37}$

\section{Medications}

Use of various medications such as NSAIDs (eg, ibuprofen, naproxen, diclofenac, or aspirin) at therapeutic doses can often be helpful. A recent network meta-analysis concluded that diclofenac, $150 \mathrm{mg} / \mathrm{d}$, is the most effective NSAID available in terms of improving both pain and function. ${ }^{41}$ Caution and attention must be focused on avoiding excessive use of these medications. In addition, consideration of all known safety information and individual patient comorbidities is imperative when the health care practitioner is selecting any of these medications for a patient.

\section{Intra-articular Knee Injections}

Intra-articular injections into the knee are an appealing option for patients because they present a low risk of harm while providing potential pain reduction and improvement in physical function. Intra-articular injections are a particularly tempting viable option in younger patients with less severe disease. Most reported intra-articular knee injections may be segregated into three groups (see Sidebar: Intra-articular Knee Injection Treatments).

\section{Surgical Options}

Surgery is indicated and should be considered when a patient is refractory to conservative, nonoperative treatment modalities have been tried for a reasonable period (at least three months), and quality of life is notably compromised. Surgical options for knee OA include multiple techniques: arthroscopy, cartilage repair, osteotomies, and knee replacement (partial and total knee arthroplasties). ${ }^{42,43}$ Multiple variables are taken into consideration and must be evaluated when determining which of these procedures is the most appropriate for a specific patient. The location and extent or severity of knee OA along with patient comorbidities and risk factors must be contemplated for any surgical candidate. ${ }^{43}$

The role of arthroscopy in knee OA is controversial. Arthroscopic lavage and débridement do not alter OA disease progression in the knee, and the benefits seen from these interventions are limited in time and by inconsistency of results. ${ }^{44,45}$ Nevertheless, knee arthroscopy may be used for any new onset of mechanical symptoms if desired, with understanding of its limitations.

If OA is limited to only one compartment of the knee joint, surgical techniques involving unicompartmental knee arthroplasty or unloading osteotomy may be considered. The goal of an osteotomy is to transfer the weight load from the damaged compartment to undamaged areas, delaying the need for joint arthroplasty. This procedure should be considered in young and active patients. ${ }^{46,47}$ An alternative in between osteotomy and total knee arthroplasty (TKA) is partial knee arthroplasty. In select patients with isolated medial, lateral, or patellafemoral OA, unicompartmental knee arthroplasty or patella-femoral replacement can be successful alternatives. ${ }^{42,43,48,49}$

Nonetheless, for patients with severe and advanced knee OA, TKA may be the only option to resolve the pain and improve function. Today, TKA has become a safe and cost-effective treatment that provides $90 \%$ to $95 \%$ pain relief and has a $1 \%$ to $2 \%$ complication rate. ${ }^{49} \mathrm{With}$ the surgical techniques and surgeon skills available today, more than $90 \%$ of the patient population undergoing a TKA will continue to report satisfactory results 20 years after the surgery. ${ }^{49}$

\section{CONCLUSION}

Knee OA is a degenerative joint disease and one of the leading causes of disability in the US and worldwide. Although disease pathophysiology is still poorly understood and is under current investigation, it is accepted that knee OA is multifactorial in origin. Multiple risk factors related to the development of knee OA are described as either nonmodifiable or modifiable. Nonmodifiable risk factors are those that are hereditary (genetic mutations that may predispose an individual to the development OA of the knee) or congenital (inherited abnormalities in the shape of the bone that surround the knee joint). Modifiable risk factors are those that can be targeted for treatment (eg, obesity) and are therefore adjustable.

Treatment designed for knee OA should be aimed at relieving pain, improving 
function, and limiting disabilities. It must focus on relieving symptoms and improving quality of life for patients. Nonoperative treatments (ie, conservative management) are the initial approach for patients who consult for the first time with knee pain and signs of knee OA. These may include modification of physical activities, weight loss for the patient with excess weight, engaging in muscle strengthening exercises, use of orthotics, application of cold or heat, pharmaceutical treatment such as NSAIDs, noninvasive electrical stimulation techniques, bracing, and intra-articular injection therapies. When nonoperative treatment fails and a patient's quality of life becomes notably compromised, surgery should be considered. Surgical options for knee OA may include knee arthroscopy, cartilage repair, osteotomies, and knee replacement (partial and total knee arthroplasties).

\section{Disclosure Statement}

The author(s) have no conflicts of interest to disclose.

\author{
Acknowledgment \\ Kathleen Louden, ELS, of Louden Health \\ Communications provided editorial assistance.
}

\section{How to Cite this Article}

Lespasio MJ, Piuzzi NS, Husni ME, Muschler GF, Guarino AJ, Mont MA. Knee osteoarthritis: A primer. Perm J 2017;21:16-183. DOI: https://doi. org/10.7812/TPP/16-183.

\section{Intra-articular Knee Injection Treatments}

\section{Viscosupplementation with hyaluronic acid (HA): Injection into the knee with $\mathrm{HA}$} (similar to the main component in cartilage) has been reported to provide temporary pain relief for up to three months. Evidence to date on use of HA has been contradictory, and recommendations regarding its use remain inconclusive. ${ }^{1,2}$ Currently, the American Academy of Orthopaedic Surgeons does not recommend using hyaluronic acid for patients with symptomatic end-stage osteoarthritis $(\mathrm{OA})$ of the knee. There are no existing data that any of the HA injections will cause regression of osteophytes, subchondral bone remodeling, or regeneration of cartilage and meniscus in patients with substantial, irreversible bone and cartilage damage. Further investigations are required to determine whether high-molecular-weight and cross-linked preparations of HA have superior efficacy compared with other HA preparations or other currently available treatments. In addition, studies involving long-term outcomes of efficacy, safety, and economic cost-benefit analyses are needed. ${ }^{2}$ Because of the paucity of data supporting the effectiveness of $\mathrm{HA}$ injections to justify their cost, careful patient selection and decreasing the use of $\mathrm{HA}$ among patients with end-stage knee OA may represent a substantial cost reduction without negatively affecting the quality of health care. ${ }^{3}$

2. Intra-articular corticosteroids: Intra-articular injections of corticosteroids have long been used to try to relieve symptoms from knee OA, but studies addressing their efficacy have been contradictory. The American Academy of Orthopaedic Surgeons guidelines for nonoperative treatment options for patients with $\mathrm{OA}$ of the knee do not recommend for or against the use of intra-articular corticosteroids into the knee. ${ }^{1}$ Furthermore, a recent Cochrane systematic review concluded that clinically important benefits of one to six weeks remain unclear because of the overall quality of the studies, the heterogeneity between trials, and presence of small-study effects. ${ }^{4}$
3. Biologics: Biologic injections include cell-based therapies and platelet-rich plasma (PRP).

a. Cell-based therapies: Cell-based therapies for knee OA are in development stages. A recent systematic review suggested that intra-articular cellular injections for $\mathrm{OA}$ and focal cartilage defects in the human knee had positive results and seemed safe. However, improvement in patient symptoms was modest and a placebo effect could not be disregarded. The overall quality of the literature was poor; therefore, accurate assessment and optimization of these therapies will require further research. ${ }^{5}$ Most of the studies analyzed reported on the use of autologous cellular therapies. Bone marrow-derived cells were the source chosen more often, followed by adipose-derived cells and blood stem cells.

b. Platelet-rich plasma: Multiple studies and systematic reviews have

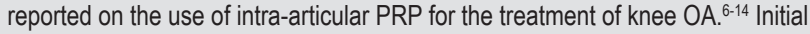
observations support an inference that PRP appears to be safe. Although some transient pain or swelling has been reported after its use, these symptoms typically resolve within two to three days, and no long-term side effects have been reported. Use of PRP, especially a lower leukocyte concentration known as leukocyte-poor PRP, showed improved results compared with HA and placebo, showing beneficial effects of amelioration in pain and improvement in function about two months after application and lasting up to a year. ${ }^{9,15-17}$ On the basis of the current evidence, although PRP injections have been demonstrated to more effectively reduce pain and improve overall physical function compared with control studies, the quality of evidence is lacking, and further research is required to establish the efficacy of using PRP as a treatment option.

\section{References}

1. AAOS: American Academy of Orthopaedic Surgeons. Treatment of osteoarthritis of the knee: Evidence-based guideline. 2nd edition [Internet]. Rosemont, IL: American Academy of Orthopaedic Surgeons; 2013 May 18 [cited 2016 Oct 10]. Available from: www.aaos.org/research/guidelines/treatmentofosteoarthritisofthekneeguideline.pdf.

2. Evaniew N, Simunovic N, Karlsson J. Cochrane in CORR囚: Viscosupplementation for the treatment of osteoarthritis of the knee. Clin Orthop Relat Res 2014 Jul;472(7):2028-34. DOI: https://doi. org/10.1007/s11999-013-3378-8.

3. Weick JW, Bawa HS, Dirschl DR. Hyaluronic acid injections for treatment of advanced osteoarthritis of the knee: Utilization and cost in a national population sample. J Bone Joint Surg Am 2016 Sep 7:98(17):1429-35. DOI: https://doi.org/10.2106/JBJS.15.01358.

4. Jüni P, Hari R, Rutjes AW, et al. Intra-articular corticosteroid for knee osteoarthritis. Cochrane Database Syst Rev 2015 Oct 22;(10):CD005328. DOI: https://doi.org/10.1002/14651858.CD005328.pub3.

5. Chahla J, Piuzzi NS, Mitchell JJ, et al. Intra-articular cellular therapy for osteoarthritis and focal cartilage defects of the knee: A systematic review of the literature and study quality analysis. J Bone Joint Surg Am 2016 Sep 21;98(18):1511-21. DOI: https://doi.org/10.2106/JBJS.15.01495.

6. Arden N, Nevitt MC. Osteoarthritis: Epidemiology. Best Pract Res Clin Rheumatol 2006 Feb;20(1):3-25. DOI: https://doi.org/10.1016/.berh.2005.09.007.

7. Wluka AE, Lombard CB, Cicuttini FM. Tackling obesity in knee osteoarthritis. Nat Rev Rheumatol 2013 Apr;9(4):225-35. DOI: https://doi.org/10.1038/nrrheum.2012.224.

8. Duivenvoorden T, Brouwer RW, van Raaij TM, Verhagen AP, Verhaar JA, Bierma-Zeinstra SM. Braces and orthoses for treating osteoarthritis of the knee. Cochrane Database Syst Rev 2015 Mar 16:(3):CD004020. DOI: https://doi.org/10.1002/14651858.CD004020.pub3.

9. Riboh JC, Saltzman BM, Yanke AB, Fortier L, Cole BJ. Effect of leukocyte concentration on the efficacy of platelet-rich plasma in the treatment of knee osteoarthritis. Am J Sports Med 2016 Mar;44(3):792-800. DOl: https://doi.org/10.1177/0363546515580787.

10. Piuzzi NS, Slullitel PA, Bertona A, et al. Hip arthroscopy in osteoarthritis: A systematic review of the literature. Hip Int $2016 \mathrm{Jan}$-Feb;26(1):8-14. DOl: https://doi.org/10.5301/hipint.5000299

11. Thorlund JB, Juhl CB, Roos EM, Lohmander LS. Arthroscopic surgery for degenerative knee: Systematic review and meta-analysis of benefits and harms. BMJ 2015 Jun 16;350:h2747. DOI: https://doi.org/10.1136/bmj.h2747.

12. Zuiderbaan HA, van der List JP, Kleeblad LJ, et al. Modern indications, results, and global trends in the use of unicompartmental knee arthroplasty and high tibial osteotomy in the treatment of isolated medial compartment osteoarthritis. Am J Orthop (Belle Mead NJ) 2016 Sep/Oct;45(6):E355-E361.

13. Loia MC, Vanni S, Rosso F, et al. High tibial osteotomy in varus knees: Indications and limits. Joints 2016 Aug 18;4(2):98-110. DOI: https://doi.org/10.11138/tts/2016.4.2.098.

14. Maduekwe UI, Zywiel MG, Bonutti PM, Johnson AJ, Delanois RE, Mont MA. Scientific evidence for the use of modern unicompartmental knee arthroplasty. Expert Rev Med Devices 2010 Mar;7(2):219-39. DOI: https://doi.org/10.1586/erd.09.65.

15. Anitua E, Sánchez M, Aguirre JJ, Prado R, Padilla S, Orive G. Efficacy and safety of plasma rich in growth factors intra-articular infiltrations in the treatment of knee osteoarthritis. Arthroscopy 2014 Aug;30(8):1006-17. DOI: https://doi.org/10.1016/j.arthro.2014.05.021.

16. Chang KV, Hung CY, Aliwarga F, Wang TG, Han DS, Chen WS. Comparative effectiveness of platelet-rich plasma injections for treating knee joint cartilage degenerative pathology: A systematic review and meta-analysis. Arch Phys Med Rehabil 2014 Mar;95(3):562-75. DOI: https://doi.org/10.1016/i.apmr.2013.11.006.

17. Khoshbin A, Leroux T, Wasserstein D, et al. The efficacy of platelet-rich plasma in the treatment of symptomatic knee osteoarthritis: A systematic review with quantitative synthesis. Arthroscopy 2013 Dec;29(12):2037-48. DOI: https://doi.org/10.1016/j.arthro.2013.09.006 


\section{References}

1. Chu CR, Millis MB, Olson SA. Osteoarthritis: From palliation to prevention: AOA critical issues. J Bone Joint Surg Am 2014 Aug 6:96(15):e130. DOI: https:// doi.org/10.2106/JBJS.M.01209.

2. Lawrence RC, Felson DT, Helmick CG, et al; National Arthritis Data Workgroup. Estimates of the prevalence of arthritis and other rheumatic conditions in the United States: Part II. Arthritis Rheum 2008 Jan;58(1):26-35. DOl: https://doi.org/10.1002/art.23176.

3. Heidari B. Knee osteoarthritis prevalence, risk factors pathogenesis and features: Part I. Caspian J Intern Med 2011 Spring;2(2):205-12.

4. Roos EM, Arden NK. Strategies for the prevention of knee osteoarthritis. Nat Rev Rheumatol 2016 Feb;12(2):92-101. DOI: https://doi.org/10.1038/ nrrheum.2015.135

5. Berenbaum F. Osteoarthritis as an inflammatory disease (osteoarthritis is not osteoarthrosis!). Osteoarthritis Cartilage 2013 Jan;21(1):16-21. DOI: https://doi.org/10.1016/j.joca.2012.11.012.

6. Daghestani HN, Kraus VB. Inflammatory biomarkers in osteoarthritis. Osteoarthritis Cartilage 2015 Nov;23(11):1890-6. DOI: https://doi.org/10.1016/j. joca.2015.02.009.

7. Greene MA, Loeser RF. Aging-related inflammation in osteoarthritis. Osteoarthritis Cartilage 2015 Nov;23(11):1966-71. DOI: https://doi.org/10.1016/j. joca.2015.01.008

8. Malfait AM. Osteoarthritis year in review 2015: Biology. Osteoarthritis Cartilage 2016 Jan;24(1):21-6. DOI: https://doi.org/10.1016/j.joca.2015.09.010.

9. Orlowsky EW, Kraus VB. The role of innate immunity in osteoarthritis: When our first line of defense goes on the offensive. J Rheumatol 2015 Mar;42(3):363-71. DOI: https://doi.org/10.3899/jrheum.140382.

10. Scanzello CR, Goldring SR. The role of synovitis in osteoarthritis pathogenesis. Bone 2012 Aug;51(2):24957. DOI: https://doi.org/10.1016/j.bone.2012.02.012

11. Sellam J, Berenbaum F. Is osteoarthritis a metabolic disease? Jt Bone Spine 2013 Dec;80(6):568-73. DOI: https://doi.org/10.1016/j.jbspin.2013.09.007.

12. Varady $\mathrm{NH}$, Grodzinsky AJ. Osteoarthritis year in review 2015: Mechanics. Osteoarthritis Cartilage 2016 Jan;24(1):27-35. DOI: https://doi.org/10.1016/j. joca.2015.08.018

13. Jordan JM, Helmick CG, Renner JB, et al. Prevalence of knee symptoms and radiographic and symptomatic knee osteoarthritis in African Americans and Caucasians: The Johnston County Osteoarthritis Project. J Rheumatol 2007 Jan;34(1):172-80.

14. Bliddal $H$, Christensen $R$. The treatment and prevention of knee osteoarthritis: A tool for clinical decision-making. Expert Opin Pharmacother 2009 Aug;10(11):1793-804. DOI: https://doi. org/10.1517/14656560903018911.

15. Zhang Y, Jordan JM. Epidemiology of osteoarthritis. Clin Geriatr Med 2010 Aug;26(3):355-69. DOI: https:// doi.org/10.1016/j.cger.2010.03.001. Erratum in: Clin Geriatr Med 2013 May:29(2):ix. DOI: https://doi. org/10.1016/j.cger.2013.01.013.

16. Arden N, Nevitt MC. Osteoarthritis: Epidemiology. Best Pract Res Clin Rheumatol 2006 Feb;20(1):3-25. DOI: https://doi.org/10.1016/j.berh.2005.09.007.

17. Kulkarni K, Karssiens T, Kumar V, Pandit H. Obesity and osteoarthritis. Maturitas $2016 \mathrm{Jul} ; 89 \cdot 22-8$. DOl: https://doi.org/10.1016/j.maturitas.2016.04.006.

18. Wluka AE, Lombard CB, Cicuttini FM. Tackling obesity in knee osteoarthritis. Nat Rev Rheumatol 2013 Apr;9(4):225-35. DOI: https://doi.org/10.1038/ nrrheum.2012.224.

19. Workgroup of the American Association of Hip and Knee Surgeons Evidence Based Committee. Obesity and total joint arthroplasty: A literature based review. J
Arthroplasty 2013 May;28(5):714-21. DOl: https://doi. org/10.1016/j.arth.2013.02.011.

20. Mahir L, Belhaj K, Zahi S, Azanmasso H, Lmidmani F, El Fatimi A. Impact of knee osteoarthritis on the quality of life. Ann Phys Rehabil Med 2016 Sep;59 (Suppl):e159. DOI: https://doi.org/10.1016/j. rehab.2016.07.355

21. Kuyinu EL, Narayanan G, Nair LS, Laurencin CT. Animal models of osteoarthritis: Classification, update and measurement of outcomes. J Orthop Surg Res 2016 Feb 2;11:19. DOI: https://doi.org/10.1186/ s13018-016-0346-5.

22. Brown TD, Johnston RC, Saltzman CL, Marsh JL, Buckwalter JA. Posttraumatic osteoarthritis: A first estimate of incidence, prevalence, and burden of disease. J Orthop Trauma 2006 NovDec;20(10):739-44. DOI: https://doi.org/10.1097/01. bot.0000246468.80635.ef.

23. Goldberg C. A practical guide to clinical medicine [Internet]. San Diego, CA: University of California San Diego School of Medicine; updated 2015 Oct [cited 2017 Jul 12]. Available from: https://meded.ucsd.edu/ clinicalmed/joints.htm.

24. Kellgren JH, Lawrence JS. Radiological assessment of osteo-arthrosis. Ann Rheum Dis 1957 Dec;16(4):494502. DOI: https://doi.org/10.1136/ard.16.4.494.

25. Zhang W, Doherty M, Peat G, et al. EULAR evidencebased recommendations for the diagnosis of knee osteoarthritis. Ann Rheum Dis 2010 Mar;69(3):483-9. DOI: https://doi.org/10.1136/ard.2009.113100.

26. Wu CW, Morrell MR, Heinze E, et al. Validation of American College of Rheumatology classification criteria for knee osteoarthritis using arthroscopically defined cartilage damage scores. Semin Arthritis Rheum 2005 Dec;35(3):197-201. DOI: https://doi. org/10.1016/j.semarthrit.2005.06.002.

27. Altman R, Asch E, Bloch D, et al. Development of criteria for the classification and reporting of osteoarthritis. Classification of osteoarthritis of the knee. Diagnostic and Therapeutic Criteria Committee of the American Rheumatism Association. Arthritis Rheum 1986 Aug;29(8):1039-49. DOI: https://doi. org/10.1002/art.1780290816.

28. Vaishya R, Pariyo GB, Agarwal AK, Vijay V. Nonoperative management of osteoarthritis of the knee joint. J Clin Orthop Trauma $2016 \mathrm{Jul}-\mathrm{Sep}$ 7(3):170-6. DOI: https://doi.org/10.1016/j.jcot.2016.05.005.

29. AAOS: American Academy of Orthopaedic Surgeons. Treatment of osteoarthritis of the knee: Evidence-based guideline. 2nd edition [Internet]. Rosemont, IL: American Academy of Orthopaedic Surgeons: 2013 May 18 [cited 2016 Oct 10]. Available from: www.aaos.org/research/guidelines/ treatmentofosteoarthritisofthekneeguideline.pdf.

30. Blagojevic M, Jinks C, Jeffery A, Jordan KP. Risk factors for onset of osteoarthritis of the knee in olde adults: A systematic review and meta-analysis. Osteoarthritis Cartilage 2010 Jan;18(1):24-33. DOI: https://doi.org/10.1016/j.joca.2009.08.010.

31. Van Manen MD, Nace J, Mont MA. Management of primary knee osteoarthritis and indications for tota knee arthroplasty for general practitioners. J Am Osteopath Assoc 2012 Nov;112(11):709-15. DOI: https://doi.org/10.7556/jaoa.2012.112.11.709.

32. Regnaux JP, Lefevre-Colau MM, Trinquart L, et al. High-intensity versus low-intensity physical activity or exercise in people with hip or knee osteoarthritis. Cochrane Database Syst Rev 2015 Oct 29;(10):CD010203. DOI: https://doi org/10.1002/14651858.CD010203.pub2

33. Scarpa R, Sarzi-Puttini P, Cimmino MA, et al. Analysis of pharmacologic and nonpharmacologic prescription patterns of general practitioners and specialists in the AMICA study. Semin Arthritis Rheum 2005 Aug:35(1 Suppl 1):24-30. DOI: https://doi.org/10.1016/j. semarthrit.2005.02.001.
34. Mitchell HL, Carr AJ, Scott DL. The management of knee pain in primary care: Factors associated with consulting the GP and referrals to secondary care. Rheumatology (Oxford) 2006 Jun;45(6):771-6. DOI: https://doi.org/10.1093/rheumatology/kei214.

35. Cherian JJ, Jauregui JJ, Leichliter AK, Elmallah RK, Bhave A, Mont MA. The effects of various physical non-operative modalities on the pain in osteoarthritis of the knee. Bone Joint J 2016 Jan;98-B(1 Suppl A):89-94. DOl: https://doi.org/10.1302/0301620X.98B1.36353.

36. Hagen KB. Canes for knee osteoarthritis: Is a randomised trial necessary? Ann Rheum Dis 2012 Feb;71(2):159-60. DOI: https://doi.org/10.1136/ ard.2011.200367.

37. Duivenvoorden T, Brouwer RW, van Raaii TM, Verhagen AP, Verhaar JA, Bierma-Zeinstra SM. Braces and orthoses for treating osteoarthritis of the knee. Cochrane Database Syst Rev 2015 Mar 16:(3):CD004020. DOI: https://do org/10.1002/14651858.CD004020.pub3

38. Mont MA, Cherian JJ, Bhave A, et al. Unloader bracing for knee osteoarthritis: A pilot study of gait and function. Surg Technol Int 2015 Nov;27:287-93.

39. Kapadia BH, Cherian JJ, Starr R, et al. Gait using pneumatic brace for end-stage knee osteoarthritis. J Knee Surg 2016 Apr;29(3):218-23. DOI: https://doi. org/10.1055/s-0036-1579790.

40. Cherian JJ, Bhave A, Kapadia BH, Starr R McElroy MJ, Mont MA. Strength and functional improvement using pneumatic brace with extension assist for end-stage knee osteoarthritis: A prospective randomized trial. J Arthroplasty 2015 May;30(5):74753. DOI: https://doi.org/10.1016/j.arth.2014.11.036.

41. da Costa BR, Reichenbach S, Keller N, et al. Effectiveness of non-steroidal anti-inflammatory drugs for the treatment of pain in knee and hip osteoarthritis: A network meta-analysis. Lancet 2016 May 21;387(10033):2093-105. DOI: https://doi.org/10.1016/ S0140-6736(16)30002-2.

42. Rönn K, Reischl N, Gautier E, Jacobi M. Current surgical treatment of knee osteoarthritis. Arthritis 2011;2011:454873. DOl: https://doi. org/10.1155/2011/454873

43. Lützner J, Kasten P, Günther KP, Kirschner S. Surgical options for patients with osteoarthritis of the knee. Nat Rev Rheumatol 2009 Jun;5(6):309-16. DOI: https://doi. org/10.1038/nrrheum.2009.88

44. Piuzzi NS, Slullitel PA, Bertona A, et al. Hip arthroscopy in osteoarthritis: A systematic review of the literature. Hip Int 2016 Jan-Feb;26(1):8-14. DOI: https://doi.org/10.5301/hipint.5000299.

45. Thorlund JB, Juhl CB, Roos EM, Lohmander LS . Arthroscopic surgery for degenerative knee: Systematic review and meta-analysis of benefits and harms. BMJ 2015 Jun 16;350:h2747. DOI: https://doi. org/10.1136/bmj.h2747.

46. Zuiderbaan HA van der List JP. Kleeblad LJ, et al. Modern indications, results, and global trends in the use of unicompartmental knee arthroplasty and high tibial osteotomy in the treatment of isolated medial compartment osteoarthritis. Am J Orthop (Belle Mead NJ) 2016 Sep/Oct;45(6):E355-E361

47. Loia MC, Vanni S, Rosso F, et al. High tibial osteotomy in varus knees: Indications and limits. Joints 2016 Aug 18;4(2):98-110. DOl: https://doi.org/10.11138/ jts/2016.4.2.098.

48. Maduekwe UI, Zywiel MG, Bonutti PM, Johnson AJ, Delanois RE, Mont MA. Scientific evidence for the use of modern unicompartmental knee arthroplasty. Expert Rev Med Devices 2010 Mar;7(2):219-39. DOl: https://doi.org/10.1586/erd.09.65

49. Carr AJ, Robertsson O Graves S, et al Knee replacement. Lancet 2012 Apr 7;379(9823):1331-40. DOI: https://doi.org/10.1016/S0140-6736(11)60752-6. 